\title{
Ocular Tuberculosis with Progressive Unilateral Corneal Melting
}

\author{
Betül N. Bayraktutar Ömür Uçakhan-Gündüz \\ Ophthalmology Department, Ankara University Faculty of Medicine, Ankara, Turkey
}

Key Words

Corneal melting $\cdot$ Ocular tuberculosis $\cdot$ Polymerase chain reaction

\begin{abstract}
Objectives: In this case report, we present a patient with ocular tuberculosis presenting with progressive unilateral corneal melting. Patient: A 47-year-old female was admitted with melting at the inferior half of the peripheral cornea and inferior subconjunctival nodules. Biopsy material of the nodules was negative for tuberculosis bacillus. However, polymerase chain reaction of the biopsy sample revealed the DNA of the bacillus, and the diagnosis was confirmed. Conclusion: In endemic areas, ocular tuberculosis should be kept in mind in the differential diagnosis of patients with chronic and atypical corneal involvement.
\end{abstract}

\section{Introduction}

Tuberculosis is one of the major causes of morbidity and mortality worldwide. According to the World Health Organization (WHO), one third of the world population is infected with Mycobacterium tuberculosis, and in 5\% of these patients primary disease develops.

Systemic tuberculosis may become manifest as pulmonary or extrapulmonary tuberculosis; pulmonary tuberculosis is responsible for $80 \%$ of active systemic disease. Ocular tuberculosis is rare; however, it can be the first clinical manifestation of the disease. Ocular involvement is the result of systemic spread of the organism through blood flow and, therefore, may affect any part of the globe [1-3].

The most common presentations of ocular tuberculosis are anterior uveitis, choroiditis and sclerokeratitis. Diagnosis can be delayed due to rare occurrence of the disease, difficulty of detection of the bacillus in the affected tissues and the low suspicion index of the ophthalmologists, leading to the development of complications with high morbidity [2,3]. Since

KARGER 125/s $\quad \begin{aligned} & \text { Betül N. Bayraktutar, MD } \\ & \text { Ophthalmology Department } \\ & \text { Ankara University Faculty of Medicine } \\ & \text { Kahire Street 7/12, TR-06660 Ankara (Turkey) } \\ & \text { E-Mail b.bayraktutar@yahoo.com }\end{aligned}$


Bayraktutar and Uçakhan-Gündüz: Ocular Tuberculosis with Progressive Unilateral Corneal Melting

tuberculosis bacillus is becoming resistant to existing antimycobacterial agents, early diagnosis and treatment is gaining more importance than ever.

In this paper, we report a patient with ocular tuberculosis who presented with unilateral progressive corneal melting.

\section{Case Report}

A 47-year-old female was admitted to our clinic with the complaint of recurrent redness, pain, foreign body sensation, corneal opacity and decreased visual acuity in her left eye. When questioned, the symptoms were noted to be present for the past 15 years. She was followed and treated with the diagnosis of peripheral ulcerative keratitis (PUK) in different clinics and investigations for an underlying immunological disease were negative. Despite different treatment regimens, such as topical antibiotics, corticosteroids and cyclosporine A drops, the whitening of the left cornea increased and visual acuity progressively deteriorated over the course of the past years.

On examination, uncorrected visual acuity was $20 / 20$ and there was no pathological finding in her right eye. In the left eye, uncorrected visual acuity was 20/200, which improved to $20 / 25$ with plano-5.00 $\times 110^{\circ}$. At slit-lamp biomicroscopy, there was no active inflammation or infiltration of the cornea; however, the inferior third of the corneal stroma was opaque and thin, with extensive limbal thinning of about 6 clock hours. There was a small dellen at 9 o'clock and two yellow subconjunctival nodules measuring $1.0 \times 1.0 \times 1.0$ $\mathrm{mm}$ and $2.0 \times 4.0 \times 1.0 \mathrm{~mm}$ in the inferior bulbar conjunctiva (fig. 1, fig. 2). There were no keratic precipitates or anterior chamber reaction, and fundus examination was normal.

Total excisional biopsies of the subconjunctival nodules were performed. Histopathological examination of the samples revealed granulomatous inflammation with caseation necrosis surrounded by multinuclear giant cells and histiocytes (fig. 3, fig. 4). Ziehl-Neelsen staining for acid fast bacilli (AFB) was negative, but on evaluation of specimens with polymerase chain reaction (PCR). M. Tuberculosis DNA was demonstrated.

The patient was referred to the Internal Medicine Department for systemic investigation, and extraocular involvement was not found in further evaluation. A 4-drug antituberculous therapy (isoniazid $300 \mathrm{mg} /$ day, rifampicin $600 \mathrm{mg} /$ day, pyrazinamide $2 \mathrm{~g} /$ day, ethambutol $800 \mathrm{mg} /$ day) was initiated. At 24 months of follow-up, ocular findings were stable and the patient remained recurrence-free.

\section{Discussion}

Tuberculosis is caused by M. tuberculosis, which is an obligate aerobe, slow-growing, nonmotile bacterium. The bacterium causes chronic and indolent systemic disease, and the organism can affect any tissue in the body. Tuberculosis is still the most common infectious disease worldwide. In the 1960s, the incidence of tuberculosis decreased significantly; however, in the 1990s, it increased because of HIV epidemics and re-emerged as a public health problem [1].

The prevalence of tuberculosis was reported to be $24 / 100,000$ in 2012 . Thirteen to fourteen thousand new cases are diagnosed per year, with $36 \%$ of these patients being diagnosed with extrapulmonary tuberculosis [1]. Therefore, ophthalmologists are at risk to face tuberculosis and its complications. Early diagnosis and treatment is important to prevent serious complications due to ocular tuberculosis. 
Bayraktutar and Uçakhan-Gündüz: Ocular Tuberculosis with Progressive Unilateral Corneal Melting

Phlyctenulosis, interstitial keratitis, conjunctival granulomas and granulomatous anterior uveitis are the most common clinical presentations [1]. Generally, corneal involvement is rare in tuberculosis. It is usually seen as unilateral inferior stromal infiltration or unilateral immune stromal interstitial keratitis due to late hypersensitivity reaction. Bilateral central interstitial keratitis [4] and bilateral disciform keratitis [5] are other atypical corneal involvements which have been reported before. Gupta et al. [6] isolated M. tuberculosis on histopathological examination of a case with Sweet's syndrome who presented with PUK and scleral nodules.

In this paper, we present a patient with ocular tuberculosis who was misdiagnosed and treated for a long time. In our patient, the major finding was chronic, insidious, progressive stromal melting unresponsive to treatment. Histopathological examination of coexisting subconjunctival nodules revealed the diagnosis of ocular tuberculosis. The presence of anterior chamber reaction was a common finding in atypical corneal involvements reported before but was not detected in our patient. Ocular tuberculosis should be considered in differential diagnosis of chronic, insidious, atypical corneal involvement, particularly in endemic areas.

In our patient, the diagnosis was confirmed by the detection of bacillus DNA with PCR in the biopsy specimen; however, Ziehl-Neelsen staining of the specimen was negative for AFB. The diagnosis of ocular tuberculosis relies on the isolation of the organism on the Löwenstein-Jensen medium, histopathologic staining methods of affected tissues or detection of the organism genome in the tissue by PCR. PCR has $95 \%$ sensitivity and specificity in the diagnosis and is more important than histopathological examination. It is suggested that in cases in which clinical and histopathological findings support the diagnosis but histopathology is negative for AFB, the biopsy specimen should be examined by PCR [1-3, 7].

In fact, PUK and interstitial keratitis are generally associated with systemic infectious and noninfectious disease such as autoimmune collagen vascular diseases. Rheumatoid arthritis is the most common etiology and accounts for $34 \%$ of noninfectious PUK cases. Other causes are Wegener's granulomatosis, relapsing polychondritis, systemic lupus erythematosus, classic polyarteritis nodosa and its variants, microscopic polyangiitis or Churg-Strauss syndrome [8].

In conclusion, although it is a rare entity, ocular tuberculosis should be considered in every case with unilateral stromal interstitial keratitis and melting, and where applicable histopathology and/or PCR should be considered in the diagnosis.

\section{Statement of Ethics}

Written informed consent was obtained from the patient.

\section{Disclosure Statement}

The authors declare no conflicts of interest.

\section{References}

Tabbara KF: Tuberculosis. Curr Opin Ophthalmol 2007;18:493-501.

Tabbara KF: Ocular tuberculosis: anterior segment. Int Ophthalmol Clin 2005;45:57-69.

Thompson MJ, Albert DM: Ocular tuberculosis. Arch Ophthalmol 2005;123:844-849. 
Case Reports in

Ophthalmology

\begin{tabular}{l|l}
\hline Case Rep Ophthalmol 2015;6:293-297 \\
\hline DOI: 10.1159/000439426 & $\begin{array}{l}\text { ○ 2015 The Author(s). Published by S. Karger AG, Basel } \\
\text { www.karger.com/cop }\end{array}$ \\
\hline
\end{tabular}

Bayraktutar and Uçakhan-Gündüz: Ocular Tuberculosis with Progressive Unilateral Corneal Melting

-4 Kamal S, Kumar R, Kumar S, Goel R: Bilateral interstitial keratitis and granulomatous uveitis of tubercular origin. Eye Contact Lens 2014;40:e13-e15.

5 Arora R, Mehta S, Gupta D, Goyal J: Bilateral disciform keratitis as the presenting feature of extrapulmonary tuberculosis. Br J Ophthalmol 2010;94:809-810.

-6 Gupta N, Chawla B, Venkatesh P, Tandon R: Necrotizing scleritis and peripheral ulcerative keratitis in a case of Sweet's syndrome found culture-positive for Mycobacterium tuberculosis. Ann Trop Med Parasitol 2008;102:557-560.

-7 Biswas J, Kumar SK, Rupauliha P, Misra S, Bharadwaj I, Therese L: Detection of mycobacterium tuberculosis by nested polymerase chain reaction in a case of subconjunctival tuberculosis. Cornea 2002;21:123-125.

$\checkmark 8$ Yagci A: Update on peripheral ulcerative keratitis. Clin Ophthalmol 2012;6:747-754.

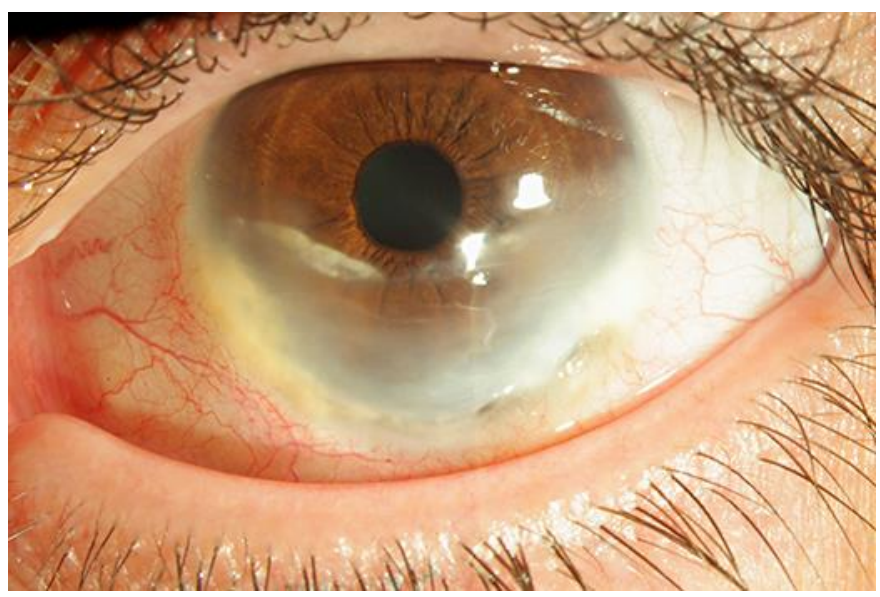

Fig. 1. Slit-lamp biomicroscopy of the left eye showing opacification of the inferior half of the cornea, whitening, 180-degree peripheral thinning and a dellen at 9 o'clock.

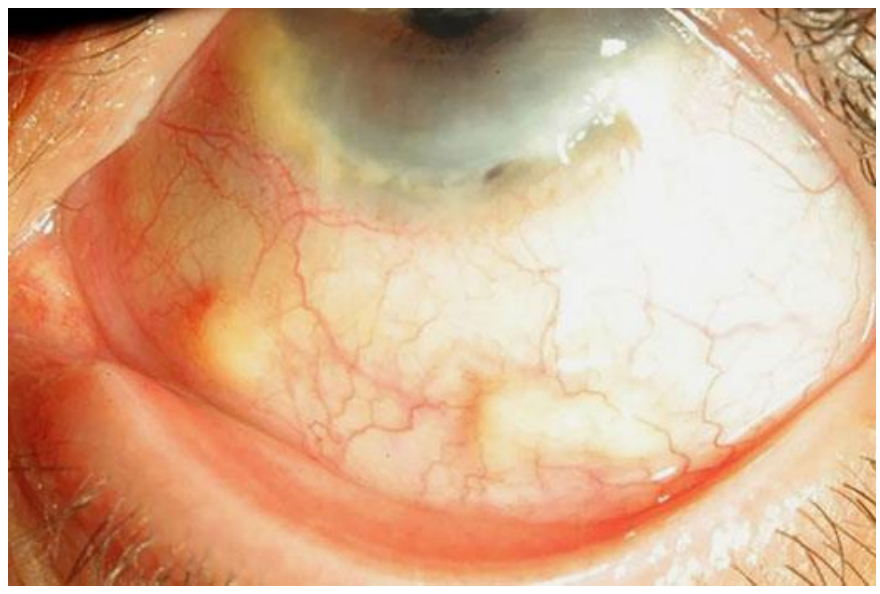

Fig. 2. Slit-lamp biomicroscopy of the same eye showing two subconjunctival nodules in the bulbar conjunctiva. 


\section{Case Reports in \\ Ophthalmology}

\begin{tabular}{l|l}
\hline Case Rep Ophthalmol 2015;6:293-297 \\
\hline DOI: 10.1159/000439426 & $\begin{array}{l}\text { @ } 2015 \text { The Author(s). Published by S. Karger AG, Basel } \\
\text { www.karger.com/cop }\end{array}$ \\
\hline
\end{tabular}

Bayraktutar and Uçakhan-Gündüz: Ocular Tuberculosis with Progressive Unilateral Corneal Melting

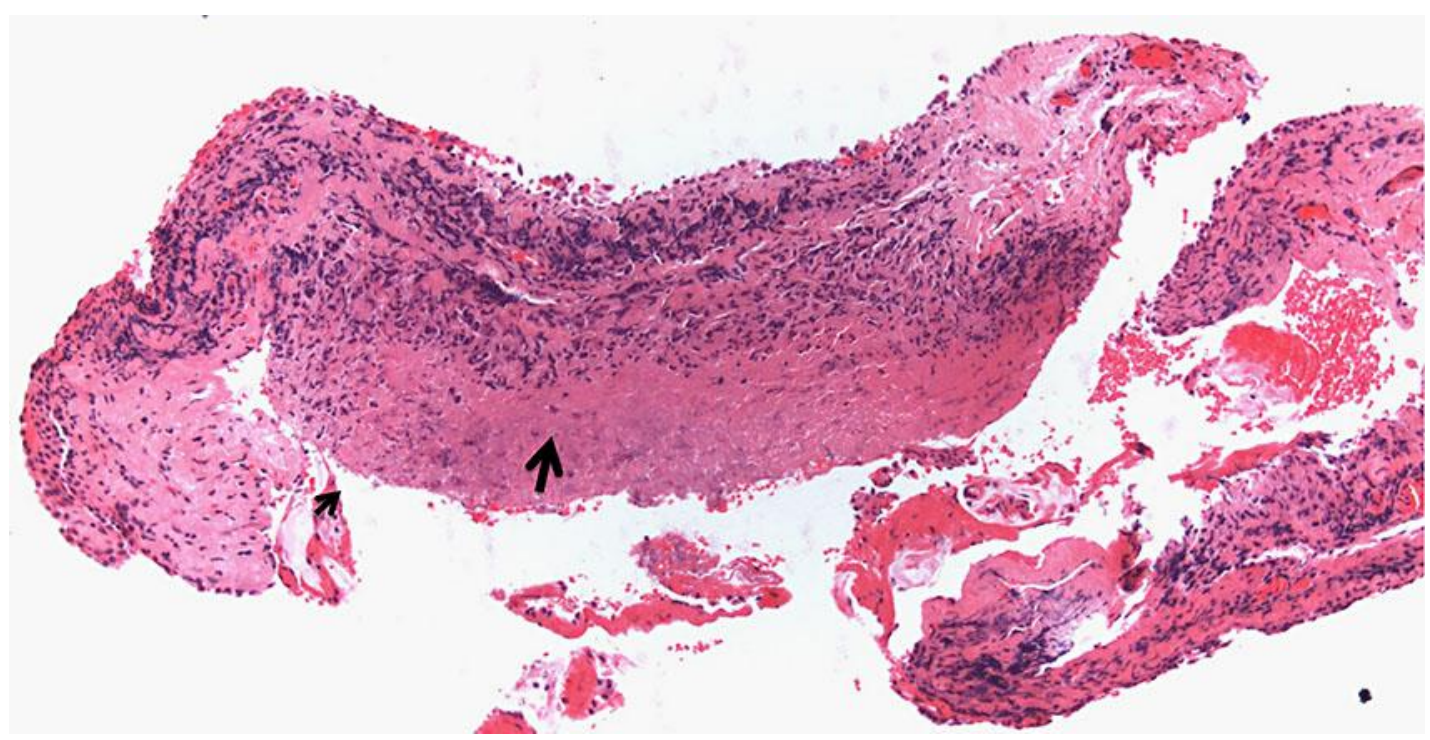

Fig. 3. Histopathology specimen of the subconjunctival nodules showing granuloma formation (small arrow) and caseation necrosis (large arrow).

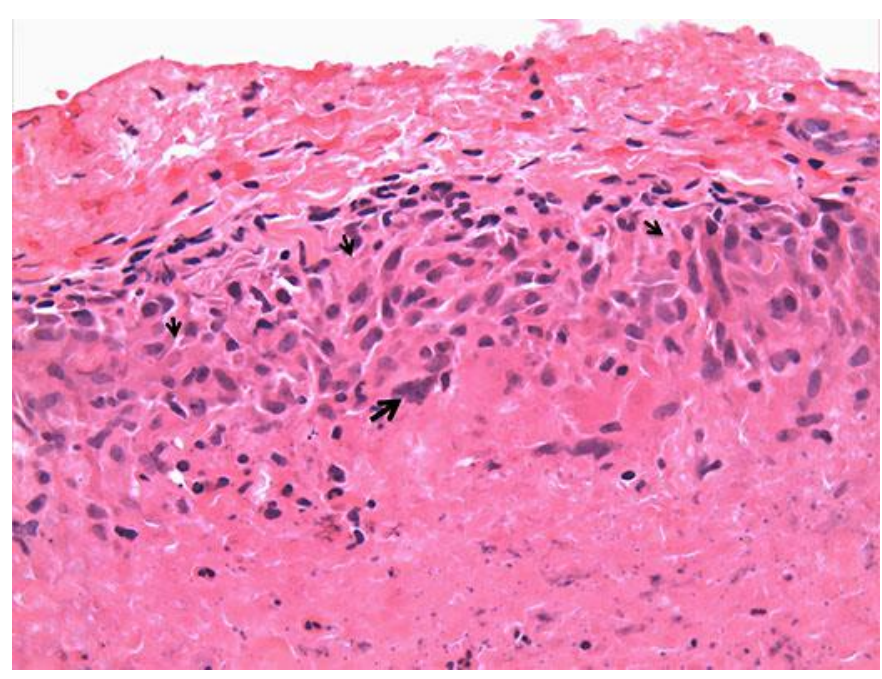

Fig. 4. The histopathology specimen at high magnification showing epithelioid histiocytes (small arrows) and multinucleated giant cells (large arrow). 